http://jmscr.igmpublication.org/home/ ISSN (e)-2347-176x ISSN (p) 2455-0450 crossref DOI: https://dx.doi.org/10.18535/jmscr/v8i2.81

\title{
Clinical Evaluation of Anti- Inflammatory Properties of Combination of Bromelain, Trypsin and Rutoside with Combination of Ibuprofen, Trypsin and Chymotrypsin following third Molar Extraction- A Comparative Study
}

Authors

\author{
Dr Lovisha Jhunjhun Wala ${ }^{1}$, Dr Ankit Choudhary ${ }^{2}$, Dr Bipin C. Reddy ${ }^{3}$
}

${ }^{1}$ BDS, MDS (Oral \& Maxillofacial Surgeon), Senior Consultant, Institute of Otorhinolaryngology \& Head and Neck Surgery, IPGMER Kolkata

${ }^{2}$ MBBS MS DNB (ENT), Senior Resident, Institute of Otorhinolaryngology \& Head and Neck Surgery,

IPGMER Kolkata

${ }^{3}$ Reader, The Oxford Dental College \& Hospital, Bangalore

\begin{abstract}
Background and Objectives: The purpose of present study is to evaluate and compare the antiinflammatory properties of combination of bromelain, trypsin and rutoside with the combination of ibuprofen, trypsin and chymotrypsin following surgical removal of lower third molar in terms of reducing postoperative pain, facial swelling and improvement in mouth opening.

Material and Methods: The study was conducted on 230 patients of either sex between the age group of 18-40 years who required removal of impacted lower third molar teeth.

Group 1:- comprising of 115 patients received the drug combination of bromelain 90mg, trypsin 48mg, rutoside 100mg for three times a day for three days.

Group 2:- comprising of 115 patients received ibuprofen 400mg, trypsin-chymotrypsin equivalent to 50,000 units for three times a day for three days.

Measurement of facial swelling, maximal mouth opening were made pre operatively and on the first, third and seventh post operative day. Pain was evaluated from patients response to visual analogue scale (VAS).

Results: Group 1 with Bromelain, trypsin and Rutoside combination showed a significant reduction in pain score when compare with group 2 at all time intervals. However no significant difference was seen in reduction of facial swelling and trismus relief was seen between the two groups. The maximum increase in swelling was seen on S3 baseline (i.e from the corner of the mouth to the angle of the mandible) in both the groups at all time periods.

Conclusion: Bromelain offers superior analgesia when compared to Ibuprofen. Bromelain and other proteolytic enzymes can be considered as an effective alternative to NSAIDs in reducing the postoperative sequelae associated with surgical extraction of third molars and causing less health hazards.

Keywords: Third molar surgery, Postoperative sequelae, Bromelain, Ibuprofen.
\end{abstract}

\section{Introduction}

Impaction of mandibular third molars is a common condition related with different difficulty degree of extraction and risk of complications. ${ }^{1}$
The surgical removal of impacted mandibular third molars is one of the most commonly performed dento-alveolar procedures, associated with varying degrees of postoperative discomfort. 
Minimal trauma to adjacent soft tissues and proper wound closure minimizes pain, swelling and trismus. ${ }^{2}$ Pharmacologic strategies for minimizing the clinical manifestations of surgical injury are therefore, logically directed at blocking the formation or inhibiting the effects of mediators of acute inflammation. ${ }^{3}$

Ibuprofen as a NSAID was reported to control mild pains and is more tolerable than other drugs of the group, and reduces the pain after tooth extraction better than aspirin, acetaminophen and acetaminophen codeine combination. NSAIDs are being used very extensively all over the world but their chronic use may lead to side effects such as gastric ulcers and liver- kidney damage. Considering these facts, the use of drugs of natural origin with lesser hazards is a positive alternative. Bromelain, Rutoside and Trypsin are known to have a very promising role in relieving inflammation and promote wound healing and based on the clinical studies performed on their combination, the Bromelain, Rutoside and Trypsin combination might be a safer alternative in comparison to other drugs used for these conditions. $^{4}$

Bromelain is a proteolytic enzyme, useful in areas of edema and inflammation. Its principle of action is by inhibiting the pro-inflammatory metabolites driving the inflammatory process. ${ }^{5}$

Trypsin is another proteolytic enzyme formed by the activation of trypsinogen. its course of action is by improving the humoral response and preventing the growth of pathogens.

Rutosideacts by inhibiting inflammatory and proarthritic mediators of macrophages. An antioxidant which blocks the harmful free radicals released during inflammation.

\section{Materials and Methods}

Two hundred and thirty patients of either sex, in the age group of 18-40 who require extraction of the lower third molar teeth, were included in the study. After obtaining complete history, patients were examined clinically and explained about the procedure, its complications and follow up period involved in the study.

Patients were divided into two equal groups on the basis of difficulty index assessed by Pederson's scale. ${ }^{7}$ Preoperatively, facial measurements and inter-incisal opening were recorded, and this was taken as baseline. The evaluations were made subsequently on 1st, 3rd and 7th post operative day and compared with baseline. Patients then underwent extraction of third molars. Regular post extraction instructions were given. All patients were given Amoxicillin 500mg thrice daily for 5 days.

Group 1:- comprising of 115 patients will receive the drug combination of bromelain $90 \mathrm{mg}$, trypsin $48 \mathrm{mg}$, rutoside $100 \mathrm{mg}$ (Thrize-DS) for three times a day for three days.

Group 2:- comprising of 115 patients will receive ibuprofen 400mg (Brufen), trypsin-chymotrypsin equivalent to 50,000 units (Chymoral-Forte) for three times a day for three days.

\section{Evaluation Criteria}

Pain was evaluated using standard visual analogue scale (VAS) on 1st, 3rd and 7th post operative day.

\begin{tabular}{lllllll}
$\mathbf{0}$ & 10 & 20 & 30 & 40 & 50 & 60 \\
\hline 70 & 80 & 90 & 100 & & &
\end{tabular}

Facial swelling was evaluated by taking measurements from six fixed points and five surgical base lines in order to cover all possible directions of extension of swelling using a measurement tape in centimetres. ${ }^{8}$

$\mathrm{S} 1$ : from the lateral canthus of the eye to the angle of the mandible.

S2: from ala of the nose to angle of the mandible.

S3: from the corner of the mouth to the angle of the mandible.

S4: from the menton to the angle of the mandible.

S5: from the ala of the nose to the tragus of the ear. 


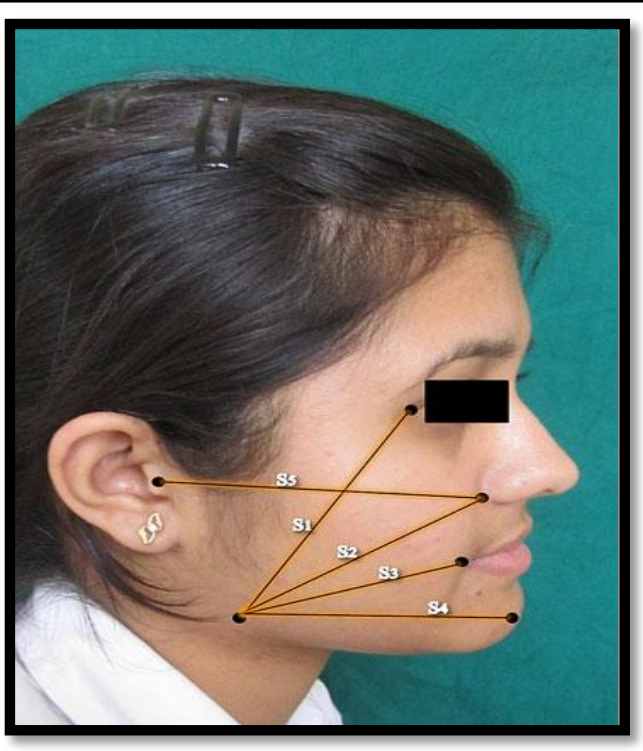

Trismus was evaluated with a metallic scale by measuring the interincisal distance preoperatively and comparing it with measurements made on postoperative days 1,3 and 7 .

\section{Results}

PAIN (Table 3 and Graph 3) - In both the groups, the mean post-operative pain score (VAS) was highest at postoperative day 1 and gradually reduced over the following 7 days. Chi-square/ Fisher Exact test was used to find the significance of pain distribution on VAS scale between the two groups. The mean postoperative pain was lower in the Bromelain (test) group at all time points when compared with the Ibuprofen (control) group.

Student-t test (Table 4 and Graph 4) was used to find the significance of comparison of pain scores on continuous scale between two groups. There is a significant difference between the test and the control group on $2^{\text {st }}, 3^{\text {rd }}$ and $7^{\text {th }}$ postoperative day $(\mathrm{p}<0.001)$.

\begin{tabular}{|l|c|c|c|}
\hline Pain & $\begin{array}{c}\text { Test } \\
\text { Group }\end{array}$ & $\begin{array}{c}\text { Control } \\
\text { Group }\end{array}$ & P value \\
\hline $1^{\text {st }}$ post op day & $3.39 \pm 1.58$ & $5.58 \pm 1.72$ & $<0.001^{* *}$ \\
\hline $3^{\text {rd }}$ post op day & $1.58 \pm 1.68$ & $3.54 \pm 1.90$ & $<0.001^{* *}$ \\
\hline $7^{\text {th }}$ post op day & $0.32 \pm 0.70$ & $0.53 \pm 0.94$ & $<0.001^{* *}$ \\
\hline
\end{tabular}

Mouth Opening (Table 5 and Graph 5)- A comparison of measurement of mouth opening is made between the test group and the control group using student t-test. The mouth opening reduced in both the groups in the postoperative period. The maximum reduction in mouth opening was seen on $1^{\text {st }}$ postoperative day which gradually improved in the following 7 days. There was no significant difference seen in the mean measurement of mouth opening between the two groups ( $p>0.05)$.

\begin{tabular}{|l|c|c|c|}
\hline Mouth Opening & $\begin{array}{c}\text { Test } \\
\text { Group }\end{array}$ & $\begin{array}{c}\text { Control } \\
\text { Group }\end{array}$ & P value \\
\hline $\begin{array}{l}\text { Preoperative Mouth } \\
\text { opening }\end{array}$ & $44.96 \pm 5.50$ & $44.70 \pm 5.55$ & 0.729 \\
\hline $\begin{array}{l}\text { Mouth opening on } 1^{\text {st }} \\
\text { post op day }\end{array}$ & $32.11 \pm 5.32$ & $32.10 \pm 5.21$ & 0.990 \\
\hline $\begin{array}{l}\text { Mouth opening on } 3^{\text {rd }} \\
\text { post op day }\end{array}$ & $37.90 \pm 6.39$ & $38.21 \pm 5.83$ & 0.706 \\
\hline $\begin{array}{l}\text { Mouth opening on } 7^{\text {th }} \\
\text { post op day }\end{array}$ & $43.87 \pm 5.52$ & $43.90 \pm 5.31$ & 0.971 \\
\hline
\end{tabular}

Swelling- Swelling was seen to be maximum on postoperative day 1 in both the test group and the control group and gradually reduced over a period of 7 days. (Table 10-11 and Graph 10-11). Maximum increase in swelling size was seen in the S3 baseline (i.e from the corner of the mouth to the angle of the mandible) in both the groups. There was no significant difference between the facial swelling on $1^{\text {st }}, 3^{\text {rd }}$ and $7^{\text {th }}$ postoperative days in both the test group and the control group $(p>0.05)$. There was a suggestive significance seen on postoperative day 3 , in S3 between the two groups ( $\mathrm{p}>0.05)$.

Table 10: Assessment of Swelling in test group

\begin{tabular}{|l|c|c|c|c|}
\hline $\begin{array}{l}\text { Swelling in } \\
\text { test group }\end{array}$ & $\begin{array}{c}\text { Pre- } \\
\text { operative }\end{array}$ & $\mathbf{1}^{\text {st }}$ post-op & $\mathbf{3}^{\text {rd }}$ post-op & $\mathbf{7}^{\text {th }}$ post-op \\
\hline S1 & $10.52 \pm 1.59$ & $10.83 \pm 1.47$ & $10.63 \pm 1.46$ & $10.47 \pm 1.50$ \\
\hline S2 & $10.95 \pm 1.40$ & $11.61 \pm 1.13$ & $11.43 \pm 1.12$ & $10.97 \pm 1.41$ \\
\hline S3 & $10.26 \pm 1.60$ & $11.20 \pm 1.27$ & $10.82 \pm 1.22$ & $10.30 \pm 1.53$ \\
\hline S4 & $11.26 \pm 1.15$ & $11.91 \pm 1.17$ & $11.59 \pm 0.92$ & $11.25 \pm 1.15$ \\
\hline S5 & $11.65 \pm 1.26$ & $11.87 \pm 1.25$ & $11.68 \pm 1.21$ & $11.65 \pm 1.26$ \\
\hline
\end{tabular}

Table 11: Assessment of Swelling in Control group

\begin{tabular}{|l|l|l|l|l|}
\hline $\begin{array}{l}\text { Swelling } \\
\text { in Control } \\
\text { group }\end{array}$ & $\begin{array}{l}\text { Pre- } \\
\text { operative }\end{array}$ & $\mathbf{1}^{\text {st }}$ post-op & $\mathbf{3}^{\text {rd }}$ post-op & $\mathbf{7}^{\text {th }}$ post-op \\
\hline S1 & $10.15 \pm 1.39$ & $10.57 \pm 1.39$ & $10.37 \pm 1.29$ & $10.23 \pm 1.38$ \\
\hline S2 & $10.93 \pm 1.30$ & $11.57 \pm 1.21$ & $11.25 \pm 1.25$ & $10.86 \pm 1.38$ \\
\hline S3 & $9.85 \pm 1.43$ & $19.99 \pm 1.20$ & $10.53 \pm 1.20$ & $10.08 \pm 1.34$ \\
\hline S4 & $11.25 \pm 1.03$ & $11.87 \pm 1.10$ & $11.63 \pm 0.94$ & $11.29 \pm 1.04$ \\
\hline S5 & $11.50 \pm 1.25$ & $11.65 \pm 1.35$ & $11.48 \pm 1.31$ & $11.54 \pm 1.27$ \\
\hline
\end{tabular}

\section{Discussion}

Nonsteroidal anti-inflammatory drugs (NSAIDs) are the most readily available and prescribed drug for the treatment of pain, inflammation and fever. Ibuprofen as an NSAIDS is useful to control mild 
to moderate pains and reduces the pain after tooth extraction better than aspirin NSAIDs cause a wide variety of side-effects. Some of the significant side-effects are upper gastrointestinal tract irritation, peptic ulcers, hemorrhage, and perforation. Recentclinical studies show that the Bromelain, Trypsin and Rutoside fixed dose combination to be a very potent and safe in relieving oedema, inflammation and promoting wound healing. 9

Bromelain is an enzyme mixture that people can extract from the stem or fruit of the pineapple plant Ananascomosus. Bromelain directly influences pain mediators such as bradykinin. Its effects are mainly of proteolytic activity. It reduces the swelling, pain and inflammation after any injury os surgical trauma. It selectively inhibits the biosynthesis of proinflammatory prostaglandins, apparently by indirect action

Rutoside Trihydrate:

Rutoside trihydrate is found in various plants such as buckwheat, apple and black tea. It has a wide array of activities such as antioxidant, antiinflammatory, anticarcinogenic, antithrombic and vasoprotective activities. ${ }^{11}$

Trypsin is in the form of the inactive zymogen trypsinogen in the which is activated into its active form trypsin by the enzyme enteropeptidase. Clinical studies exhibit that the anti-inflammatory effect of trypsin is possibly due to inhibitory action on the vascular permeability and its ability to inhibit the rise in C-reactive protein and enhance the rise in alpha 1-antitrypsin, alpha 2macroglobulin. Trypsin-chymotrypsin has also been shown to modulate cytokine levels in burns.

The most common postoperative complications after the extraction of an impacted wisdom tooth are a direct consequence of the inflammatory response to the surgical procedure and include pain, inflammation and difficulty opening the mouth. Consistent with published data, third molar surgery in both the groups were associated with significant postoperative sequelae. The postoperative sequelae including pain, trismus and facial swelling reached its peak on 1st day post operatively and gradually reduced to reach near pre operative (baseline) values by the 7th post operative day in both the groups.

The study showed that bromelain given along with trypsin and rutoside provided superior analgesia when compared with the combination of ibuprofen, trypsin and chymotrypsin. The mean postoperative pain was lower in the Bromelain group at all time points when compared with the Ibuprofen group. A significant difference in mean pain score was seen in between the two groups on $1^{\text {st }}, 3^{\text {rd }}$ and $7^{\text {th }}$ postoperative days $(\mathrm{p}<0.001)$. In the present study, there was no significant difference in trismus relief measured by maximum interincisal distance preoperatively and compared on $1^{\text {st }}, 3^{\text {rd }}$ and $7^{\text {th }}$ postoperative day. The present study showed no significant difference in swelling in the Bromelain (test) group at all time points when compared with the Ibuprofen (control) group. However, a suggestive significance was seen on postoperative day 3 , in $\mathrm{S} 3$ value between the two groups, indicating a probability of improved reduction in edema with the use of bromelain.

\section{Conclusion}

The results of this study highlights the efficacy of Bromelain, trypsin and rutoside combination in controlling the complications following surgical removal of third molar and offering a superior analgesia. Based on the analysis of the data, it can be concluded that Bromelain offers superior analgesic efficacy when compared with Ibuprofen. Bromelain and other proteolytic enzymes can be considered as an effective alternative to NSAIDs in reducing the discomfort associated with surgical extraction of third molars and causing less health hazards.

\section{References}

1. Juodzbalys G, Daugela P. Mandibular Third Molar Impaction: Review of Literature and a Proposal of a Classification. J Oral Maxillofac Res 2013 Apr-Jun;4(2). 
2. Chappi MD, Suresh KV, Patil MR, Desai R, Tauro DP, Bharani SKNS et al. Comparison of clinical efficacy of methylprednisolone and serratiopeptidase for reduction of postoperative sequelae after lower third molar surgery. J Clin Exp Dent 2015;7(2):e197-202.Availablefrom: URL:http://www.medicinaoral.com/odo/v olumenes/v7i2/jcedv7i2p197.pdf.

3. Nazar MN, Puthiriraj V. Analgesics Following Mandibular Third Molar Surgery. IJPCR 2014 Jan-Mar;6(1):13-19.

4. Kaur R, Abmwani S, Mehta B. Trypsin, rutoside and Bromelain alone and fixed dose combination: a natural, safer and effective anti - inflammatory agent. Journal of Drug Delivery and Therapeutics 2014;4(1):108-10.

5. Zamiri B, Mousavizadeh K, Tajoddini M, Mohammadinezhad C, Aarabi AM. Comparison of Ibuprofen, Celecoxib and Tramadol in Relief of Pain after Extraction of Mandibular ThirdMolar Teeth. IRCMJ 2009;11(4):431-436.

6. Ozkan BT, Durmus E, Kalayci A, Kurban S, Akca CN. The Evaluation of Safety and Analgesic Efficacy of Paracetamol and Ibuprofen Followed by Impacted Third Molar Surgery. Eur J Gen Med 2010;7(3):310-6.

7. Januja OS, Baig Z, Manzoor A, Abbas T. Accuracy of Pederson scale and modified Parant scale for predicting difficulty level of mandibular third molars. Arch Orofac Sci 2013;8(1):9-13.

8. Arakeri G, Rai KK, Shivakumar HR, Jayade B. A randomized clinical trial to compare the efficacy of submucosal aprotinin injection and intravenous dexamethasone in reducing pain and swelling after third molar surgery: A prospective study. J Maxillofac Oral Surg 2013;12(1):73-9.

9. Inchingolo $\mathrm{F}$, Tatullo $\mathrm{M}$, Marrelli $\mathrm{M}$, Inchingolo AM, Picciariello V, Inchingolo
AD et al. Clinical trial with Bromelain in third molar exodontias. Eur Rev Med Pharmacol Sci 2014;14:771-4

10. Nunez BM, Vico YRM, Cruzado BA, Saavedra HJM, OyagueR, Lagares LD. Prospective double blind clinical trial evaluating the effectiveness of Bromelain in the third molar extraction post operative period. Med Oral Patol Oral Cir Buccal 2014Mar;1:e157-62.Available from: URL: http://www.medicinaoral.com/pubmed/me doralv19_i2_p157.pdf(accessed September 2014).

11. Wani SS, Mashru RC. Determination of Specific proteolytic activity of Trypsin and Bromelain and simultaneous estimation of Rutoside Trihydrate, Diclofenac sodium, Trypsin and Bromelain in tablet formulation. Int $\mathbf{J}$ PharmTech Res 2014;6(4):1236-44. 